\title{
Identification and analysis of YELLOW protein family genes in the silkworm, Bombyx mori
}

\author{
Ai-Hua Xia ${ }^{\dagger 3}$, Qing-Xiang Zhou ${ }^{\dagger 1,3}$, Lin-Lin $\mathrm{Yu}^{3}$, Wei-Guo Li ${ }^{1}$, Yong-Zhu Yi \\ Yao-Zhou Zhang*2 and Zhi-Fang Zhang*3
}

\begin{abstract}
Address: ${ }^{1}$ The Sericultural Research Institute, Chinese Academy of Agricultural Sciences, Zhenjiang City, Jiangsu Province, 212018, China, 2Institute of Biochemistry, Zhejiang Sci-Tech University, Hangzhou, Zhejiang Province, 310018, China and ${ }^{3}$ The Biotechnology Research Institute, National Engineering of crop germplasm and genetic improvement, Chinese Academy of Agricultural Sciences, Beijing, 100081, China

Email: Ai-Hua Xia - tinyhuahua@163.com; Qing-Xiang Zhou - qxzhou2001@yahoo.com; Lin-Lin Yu - linlinyu1983@126.com; WeiGuo Li - weiguolesd@126.com; Yong-Zhu Yi - yongzhuyi62@yahoo.com; Yao-Zhou Zhang* - yaozhou@chinagene.com; Zhi-

Fang Zhang* - zhifangzhang@yahoo.com

* Corresponding authors †Equal contributors
\end{abstract}

Published: 03 August 2006

BMC Genomics 2006, 7:195 doi:10.1186/147|-2164-7-195
Received: 08 May 2006

Accepted: 03 August 2006

This article is available from: http://www.biomedcentral.com/I47/-2/64/7//95

(c) 2006 Xia et al; licensee BioMed Central Ltd.

This is an Open Access article distributed under the terms of the Creative Commons Attribution License (http://creativecommons.org/licenses/by/2.0), which permits unrestricted use, distribution, and reproduction in any medium, provided the original work is properly cited.

\begin{abstract}
Background: The major royal jelly proteins/yellow (MRJP/YELLOW) family possesses several physiological and chemical functions in the development of Apis mellifera and Drosophila melanogaster. Each protein of the family has a conserved domain named MRJP. However, there is no report of MRJP/YELLOW family proteins in the Lepidoptera.

Results: Using the YELLOW protein sequence in Drosophila melanogaster to BLAST silkworm EST database, we found a gene family composed of seven members with a conserved MRJP domain each and named it YELLOW protein family of Bombyx mori. We completed the CDNA sequences with RACE method. The protein of each member possesses a MRJP domain and a putative cleavable signal peptide consisting of a hydrophobic sequence. In view of genetic evolution, the whole $\mathrm{Bm}$ YELLOW protein family composes a monophyletic group, which is distinctly separate from Drosophila melanogaster and Apis mellifera. We then showed the tissue expression profiles of $\mathrm{Bm}$ YELLOW protein family genes by RT-PCR.

Conclusion: A Bombyx mori YELLOW protein family is found to be composed of at least seven members. The low homogeneity and unique pattern of gene expression by each member among the family ensure us to prophesy that the members of $B m$ YELLOW protein family would play some important physiological functions in silkworm development.
\end{abstract}

\section{Background}

Major royal jelly proteins and YELLOW proteins in Insecta, together with an orphan protein found in Deinococcus radiodurans, a radiation tolerant bacterium, form a protein family named the MRJP/YELLOW family [1,2]. Major royal jelly proteins (MRJPs) are initially identified as the major content of royal jelly (RJ) proteins, constitut- ing $80 \%-90 \%$ of the total RJ proteins which play a central role in the honeybee development [3]. A recent report indicates that MRJP/YELLOW protein family in Apis mellifera includes at least 8 MRJPs (named MRJP1-8) and two homologues of the Drosophila YELLOW proteins, Am-YELLOW and Am-YELLOW-f [2]. Most MRJPs have the characteristic that there are repetitive segments encoding long 
homopetptides at the carboxyl terminal. The structure is thought of as the accessible form of storing nutrition [4]. Apis mellifera MRJP/YELLOW proteins may have higher physiological functions because at least one of the members expresses in the brain's mushroom body of the honeybee [5]. At the N-terminal of MRJP/YELLOW protein, there is a strong hydrophobic sequence functioning as putative signal peptide [6]. It should be noted that the term MRJP was created before knowing their physicochemical properties. Later it was established that these proteins have physico-chemical properties similar to those of ovalbumin (storage egg-white protein) or serum albumin (major protein of serum) which are typical albunoid proteins and therefore researchers have proposed to rename major royal jelly proteins as apalbumins. Thus, apalbumin-1 will be designated as MRJP1, apalbumin-2 as MRJP2, and so on. This new terminology of honeybee larval diet proteins corresponds with reality that these proteins are presented not only in royal jelly, but also in worker and drone jellies [7].

The Drosophila yellow gene is related to normal larval and adult pigmentation and movement, and the mating behavior of male and female [8-10]. It encodes a simple transcription unit of two exons, encoding a 541 aa protein. Further researches indicate several novel Drosophila genes possessing a high identical MRJP conserved domain are termed as the yellow family [1]. With the achievement of the Drosophila melanogaster genome-sequencing project [11], the Drosophila melanogaster yellow gene family has grown to a total of more than 14 genes [12]. The Drosophila melanogaster yellow- $y$ and ebony genes together determine the degree of melanization and its pattern [13]. The yellow- $f$ and yellow- $f 2$ genes have dopachrome-conversion enzyme activity that likely playing an important role during melanin biosynthesis in Drosophila melanogaster larvae, pupae and adults [14]. Furthermore, MRJP-like protein was also found and identified in the blood-sucking insect, possessing an agglutinin activity and probably intermediating in the evolution from yellow-like function towards royal jelly components [15].

To date, no related protein has been found in the noninsect metazoans except the orphan protein in the red pigmented bacterium $D$. radiodurans with $59 \%$ similarity to the Drosophila Yellow protein [16]. However, there is no report of a MRJP/YELLOW family protein in the Lepidoptera. With the declaration of the completion of EST library $[17,18]$ and the achievement of genome sequence draft project $[19,20]$ in Bombyx mori, the silkworm, as a model organism has been attracting more scientists. We searched the silkworm EST library by the BLAST method and found eight partial MRJP/YELLOW family genes in Bombyx mori. Using the SMART ${ }^{\mathrm{TM}}$ RACE Amplification method we completed seven of the cDNA sequences. The nucleotide acid and amino acid structures of the genes were analyzed, and the tissue expression profiles and phylogenetic analysis were also studied.

\section{Results \\ Identification of $\mathrm{Bm}$ YELLOW protein family in the EST library}

We obtained 74 ESTs of different length from the silkworm EST library, using the conserved domain in Yellow protein of Drosophila melanogaster to BLAST. We grouped and combined these sequences using the programs of DNASTAR and CLUSTAL X software packages. Seven Bm YELLOW protein family genes (GenBank: DQ358079DQ358085) (Table 1) each contained a MRJP conserved domain were gained.

\section{Sequence analysis in Bm YELLOW protein family Bm-yellow-d}

The biggest group consisted of 21 ESTs derived from midgut, wing discs, ovary, fat body and pheromone gland. The assembled contig contained 1,510 nucleotide acids with incomplete 3'-terminal. Primers (Table 2) were designed depending on the assembled sequence, and 3'RACE was performed using midgut cDNA as the template. Then the obtained 3'-RACE product was combined with the assembled contig and named Bm-yellow-d. The sequence of Bm-yellow- $d$ was 1,678 bp long, containing an open reading frame of $1,341 \mathrm{bp}$ encoding a protein 446 amino acids long. The stop codon was located $159 \mathrm{bp}$ upstream of the poly (A) tail and no usual polyadenylation (AAUAAA) signal was found. The first 24 amino acids of the protein made a putative signal peptide and the location between amino acid residue 122 and residue 412 was the MRJP conserved domain.

The sequence of the Bm-yellow- $d$ cDNA was almost completely covered by the sequence (GenBank: $\underline{\text { AADK01006220, }}$ AADK01006404, AADK01009017) readings from shotgun sequencing of the silkworm genome. This enabled us to identify the 6 introns in the genomic locus of Bm-yellow-d. Considering the incompleteness of the fifth intron, two primers (5'-gtttccaacgtgggaagactta, 5'-cgagaaacgtcgatactgtgtt) for PCR were designed basing on known sequences (GenBank: AADK01006404, AADK01009017), to complete the genomic sequence of Bm-yellow-d. Surprisingly, we got several amplification products of different sizes and the sequencing results showed that there might be an extensively high repeat area.

\section{Bm-yellow-fa}

Fifteen ESTs from pheromone gland, fat body or embryo were combined in an assembled contig 1,274 bp long absent 3'-terminal. After combined with the 3'-RACE product from pheromone gland, a 1,543 bp cDNA was 
Table I: The gene family encoding YELLOW-like proteins in Bombyx mori

\begin{tabular}{|c|c|c|c|c|c|c|c|c|c|}
\hline \multirow{12}{*}{ 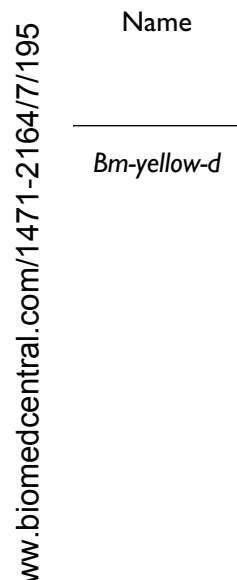 } & \multicolumn{2}{|c|}{ Related ESTs } & \multirow{2}{*}{$\begin{array}{c}\text { Introns } \\
6\end{array}$} & \multirow{2}{*}{$\begin{array}{c}\text { Resource } \\
\text { middle gut/wing discs/ovary/fat body/pheromone gland }\end{array}$} & \multirow{2}{*}{$\begin{array}{c}\begin{array}{c}\text { cDNA length } \\
\text { (without Poly(A) } \\
\text { tail) }\end{array} \\
1,678\end{array}$} & \multirow{2}{*}{$\begin{array}{c}\text { Aa length } \\
446\end{array}$} & \multirow{2}{*}{$\begin{array}{l}\text { MRJP Domain } \\
\text { (aa) } \\
|22-4| 2\end{array}$} & \multirow{2}{*}{$\begin{array}{c}\text { Genbank } \\
\text { accession no. } \\
\underline{\text { DQ358079 }}\end{array}$} & \multirow{2}{*}{$\begin{array}{l}\begin{array}{c}\text { Best similar to } \\
\text { Drosophila yellow } \\
\text { family }\end{array} \\
\text { yellow-d } \\
\text { AAF46993 }\end{array}$} \\
\hline & BPI82942 & AV404254 & & & & & & & \\
\hline & BPI83166 & BPI 25346 & & & & & & & \\
\hline & BPI 82340 & BPI79547 & & & & & & & \\
\hline & BPI83224 & BPI83682 & & & & & & & \\
\hline & $\mathrm{BPI} 82019$ & BPI83202 & & & & & & & \\
\hline & AV405837 & BPI83102 & & & & & & & \\
\hline & BPI828I6 & BPI 82382 & & & & & & & \\
\hline & CK5I 2445 & BPI80I56 & & & & & & & \\
\hline & CK505477 & CK5II923 & & & & & & & \\
\hline & BPI83653 & BPI8I234 & & & & & & & \\
\hline & BPI84I92 & & & & & & & & \\
\hline \multirow[t]{8}{*}{$B m$-yellow-fa } & CK514230 & CK564458 & 12 & embryo/fat body/pheromone gland & 1,543 & 459 & $168-456$ & DQ358080 & $\begin{array}{l}\text { yellow-f } \\
\text { AAF54884 }\end{array}$ \\
\hline & BPI 83402 & BPI82360 & & & & & & & \\
\hline & BPI84I63 & BPI83579 & & & & & & & \\
\hline & CK559440 & CK5I4784 & & & & & & & \\
\hline & BPI 82690 & BPI82984 & & & & & & & \\
\hline & CK5I8098 & BPI83857 & & & & & & & \\
\hline & CK556095 & CK559196 & & & & & & & \\
\hline & BPI83954 & & & & & & & & \\
\hline \multirow[t]{5}{*}{ Bm-yellow-c } & BPI82634 & BPI82782 & $>=9$ & pheromone gland/ovary/fat body & 1,916 & 407 & $118-406$ & $\underline{D Q 358081}$ & $\begin{array}{l}\text { yellow-c } \\
\text { AAF54432 }\end{array}$ \\
\hline & BPI84230 & BPI82899 & & & & & & & \\
\hline & BPI8350I & BPI83088 & & & & & & & \\
\hline & BPI 79823 & CK513620 & & & & & & & \\
\hline & BPI82645 & BPI82022 & & & & & & & \\
\hline \multirow[t]{2}{*}{ Bm-yellow-fb } & CK559703 & AV398849 & 8 & ovary/embryo/fat body & 1,516 & 418 & $|32-4| 6$ & $\underline{\mathrm{DO} 358082}$ & $\begin{array}{l}\text { yellow-f } \\
\text { AAF54884 }\end{array}$ \\
\hline & CK5I374I & & & & & & & & \\
\hline Bm-yellow-b & BPI83406 & & 0 & pheromone gland & 2,045 & 457 & $|35-4| 3$ & $\underline{\mathrm{DO} 358083}$ & $\begin{array}{l}\text { yellow-b } \\
\text { AAF59358 }\end{array}$ \\
\hline$B m-y e l l o w-f 2$ & BPII7I52 & AU00540I & $>=5$ & brain/ovary & 1,130 & 284 & $125-216$ & $\underline{\mathrm{DQ} 358084}$ & $\begin{array}{l}\text { yellow-f2 } \\
\text { AAF54885 }\end{array}$ \\
\hline \multirow[t]{5}{*}{ Bm-yellow } & BPII9072 & BPII793I & $>=3$ & ccompound eye/pheromone gland/ovary/fat body & 1,947 & 514 & $115-399$ & $\underline{\mathrm{DQ} 358085}$ & $\begin{array}{l}\text { yellow } \\
\text { AAF45497 }\end{array}$ \\
\hline & BPII 7822 & BPII7205 & & & & & & & \\
\hline & BPII 8364 & AU005349 & & & & & & & \\
\hline & BPII 7579 & BPII7226 & & & & & & & \\
\hline & BPII 8757 & BPII 8666 & & & & & & & \\
\hline
\end{tabular}


Table 2: Primers used for 3'-RACE and RT-PCR

\begin{tabular}{|c|c|c|}
\hline Primer name & Primers for 3'-RACE & Primers for RT-PCR \\
\hline Bm-yellow-d & $\begin{array}{l}\text { ATCGCTGTTGACAAAGAAACCCTGCA (1) } \\
\text { CACGTCCAGTTTTCAACGAGTAATGAC (2) }\end{array}$ & $\begin{array}{l}\text { ATCGCTGTTGACAAAGAAAC (F) } \\
\text { GGCGCTGTGTCATTTCTGTAG (R) }\end{array}$ \\
\hline Bm-yellow-fa & $\begin{array}{l}\text { GAGCGACGGAATATTCAGTCTGACTA (I) } \\
\text { TTCCATCCTTTGATCAGCACGCACGA (2) }\end{array}$ & $\begin{array}{l}\text { TTCCATCCTTTGATCAGCACGCACGA (F) } \\
\text { TCTAGCATAACCGAAACGCGGCA (R) }\end{array}$ \\
\hline Bm-yellow-c & $\begin{array}{l}\text { CTGGTCTTGCTGATATTTGGGGTG }(1) \\
\text { GAGGACATGAAAGAGGATTCATTCT }(2)\end{array}$ & $\begin{array}{l}\text { ACCTCGAGAGAACGGATTCCGAA (F) } \\
\text { CGACCAGGATCCACATTAAGCCT (R) }\end{array}$ \\
\hline Bm-yellow-fb & $\begin{array}{l}\text { GGATCCGAAGGTATGGGTCAATG (I) } \\
\text { CCTACATAACGGACTTGGCGACTA (2) }\end{array}$ & $\begin{array}{l}\text { CCTACATAACGGACTTGGCGACTA (F) } \\
\text { AATACACTACTCGGTCCGTGG (R) }\end{array}$ \\
\hline Bm-yellow-b & $\begin{array}{l}\text { CGATAACGCCATCGGTAACTGCA (I) } \\
\text { GATTCTCGATAACGGACGAGTGG (2) }\end{array}$ & $\begin{array}{l}\text { AGGTATTGCATCGATCGCTG (F) } \\
\text { GACTAAGCAAGCAGGTGTGCT (R) }\end{array}$ \\
\hline Bm-yellow-f2 & $\begin{array}{l}\text { GGATATCCCAGGTATAAGGAAGC (I) } \\
\text { CCGCATTTCAGGAAAGACATCGA (2) }\end{array}$ & $\begin{array}{l}\text { GGATATCCCAGGTATAAGGAAGC (F) } \\
\text { GTAATCTGCGCGATTTTGCGCT (R) }\end{array}$ \\
\hline Bm-yellow & $\begin{array}{l}\text { TCACCTCTGAGCAGTCACACAGAA (1) } \\
\text { TCGACCCGTATCTTGAGAGACGAA (2) }\end{array}$ & $\begin{array}{l}\text { TCGACCCGTATCTTGAGAGACGAA (F) } \\
\text { TGTGCCTGAAGCACTGGCAATG (R) }\end{array}$ \\
\hline Nup and Actin & Nup: AAGCAGTGGTATCAACGCAGAGT & $\begin{array}{l}\text { Actin-F: CCCCATCGAACACGGAATCG } \\
\text { Actin-R: CGCTCGGCAGTGGTAGTGAA }\end{array}$ \\
\hline
\end{tabular}

gained and named Bm-yellow-fa. Bm-yellow-fa contained an open reading frame of $1,380 \mathrm{bp}$ encoding a protein 459 amino acids long. The stop codon was located $164 \mathrm{bp}$ upstream of the poly (A) tail, 31 bp upstream of which was a consensus polyadenylation signal (AAUAAA). A putative signal peptide was found in the first 17 amino acids of the protein. The complete MRJP conserved region stretched from residues 168 to 456.

Shotgun sequence readings of the silkworm Genome (GenBank: BAAB01099246, BAAB01003180, BAAB01177891, AADK01031417, BAAB01168441, BAAB01050009, AADK01029979) could cover the whole of the Bm-yellowfa cDNA. That enabled us to deduce that the genomic locus of Bm-yellow-fa contained 12 introns.

\section{Bm-yellow-c}

$B m-$ yellow-c was combined by the assembled contig 1,274 bp long, consisting of 10 ESTs from pheromone gland, ovary and fat body, and the 3'-terminal fragment obtained by 3 '-RACE from pheromone gland. The gene was composed of 1,916 bp and contained an open reading frame of 1,224 bp, encoding a protein 407 amino acids long with a putative signal peptide in the first 18 amino acids and a MRJP conserved region in 118-406 amino acid residues. The stop codon was located $633 \mathrm{bp}$ upstream of the poly (A) tail. No typical polyadenylation (AAUAAA) signal was found.

Shotgun sequence readings of the silkworm Genome (GenBank: $\quad$ BAAB01124731, $\quad$ AADK01025556, BAAB01064927， AADK01021354， BAAB01083903, AADK01026184) covered partial of the Bm-yellow-c cDNA, which enabled us to conclude at least 9 introns were contained in the genomic locus of Bm-yellow-c.

\section{Bm-yellow-fb}

A 941 bp long assembled contig consisted of 3 ESTs from pheromone gland, fat body or embryo. We obtained the 3'-terminal fragment by 3'-RACE from ovary and combined as the Bm-yellow-c gene 1,516 bp long. The gene contained an open reading frame of 1,257 bp, encoding a protein 418 amino acids long, with a putative signal peptide in the first 20 amino acids and a MRJP conserved region spanning 132-416 amino acid residues. The stop codon was located 188 bp upstream of the poly (A) tail, 14 bp upstream which was the consensus polyadenylation signal (AAUAAA).

Shotgun sequence reading of the silkworm Genome (GenBank: $\quad$ BAAB01155212, AADK01037111, AADK01031942) covered all the Bm-yellow-fb cDNA. That enabled us to conclude that the genomic locus of Bm-yellow- $f b$ contained 8 introns.

Bm-yellow-b

The EST from pheromone gland (GenBank: BP183406) 656 bp long fell in the smallest contig. We got a long 3'RACE product from pheromone gland and assembled it with the EST sequence, and obtained the 2,045 bp Bm-yellow- $b$ gene. The gene contained an open reading frame of $1,374 \mathrm{bp}$, encoding a protein 457 amino acids long with a putative signal peptide in the first 26 amino acids and a MRJP conserved domain spanning 135-413 amino acid residues. The stop codon was located 640 bp upstream of the poly (A) tail, and a consensus polyadenylation signal (AAUAAA) was located only 12 bp upstream of the tail.

Shotgun sequence readings of the silkworm Genome (GenBank: BAAB01152328, AADK01044238) covered the whole cDNA of $B m-y e l l o w-b$ and no intron was identified in the genomic locus of Bm-yellow-b. 


\section{Bm-yellow-f2}

Two ESTs from ovary and brain composed an assembled contig 731 bp long. The 3'-terminal fragment was obtained by 3'-RACE from ovary and combined with the former assembled contig, composing the cDNA of Bm-yellow-f2, which was 1,130 bp long. Bm-yellow- $f 2$ cDNA contained an open reading frame of $855 \mathrm{bp}$, encoding a protein 284 amino acids long with a putative signal peptide in the first 17 amino acids and an incomplete MRJP conserved region spanning 125-216 amino acid residues. The stop codon was located 259 bp upstream of the poly (A) tail, while no consensus polyadenylation signal (AAUAAA) was found.

Shotgun sequence readings of the silkworm Genome (GenBank: AADK01003428, AADK01027742) covered partial of the cDNA of Bm-yellow- $f 2$. That enabled us to conclude that at least 5 introns were contained in the genomic locus of Bm-yellow- $f 2$.

\section{Bm-yellow}

A 1,045 bp assembled contig consisted of 10 ESTs from compound eye, pheromone gland, ovary and fat body was named Bm-yellow. With the result of 3'-RACE, we got a cDNA of 1,947 bp contained a complete open reading frame, encoding a protein of 514 amino acids. A putative signal peptide was found in the first 18 amino acids and a MRJP conserved domain was located from 115 to 399 amino acid residues. The stop codon was located $373 \mathrm{bp}$ upstream of the poly (A) tail, and a consensus polyadenylation signal (AAUAAA) was found located $17 \mathrm{bp}$ upstream of the poly (A) tail.

Shotgun sequence readings of the silkworm Genome (GenBank: BAAB01161029, AADK01014604) covered partial of the Bm-yellow cDNA. It showed that no less than 3 introns were in the genomic locus of Bm-yellow.

\section{Alignment and phylogeny of Bm YELLOW protein family proteins}

Homology alignment was performed between the YELLOW protein families of Drosophila melanogaster and Bombyx mori at amino acid sequence level. The result showed that $B m$-YELLOW- $d$ shared the highest identity with YELLOW-d2 among Drosophila melanogaster YELLOWfamily (38.8\%). Bm-YELLOW- $f a$ and Bm-YELLOW- $f b$ both shared the highest identity with YELLOW-f (42.9\% and $35.1 \%$, respectively), while $B m$-YELLOW-f2 shared with YELLOW-f2 (21.1\%). Bm-YELLOW-c shared the highest identity with YELLOW-c (50.5\%), and Bm-YELLOW- $b$ was the most similar to YELLOW- $b$ with an identity of $23 \%$. Bm-YELLOW was mostly homologous to Drosophila melanogaster YELLOW (51.2\%).
The protein sequences of the $B m$ YELLOW protein family, with $D m$-YELLOW and Am-YELLOW, were aligned using the CLUSTAL X software package and modified by GeneDoc software (Figure 1). The homology existed in the MRJP conserved domain of all the Bm-YELLOW family genes, but its similarity was lower than that of the Apis mellifera MRJP/YELLOW protein family and the Drosophila melanogaster YELLOW protein family. For example, though Bm-YELLOW-fa and Bm-YELLOW- $f b$ shared the highest identity, it was only $41.3 \%$. Surprisingly, some unique amino acid sequences were found in the members of the $B m$ YELLOW protein family such as residues 53 to 106 in Bm-YELLOW- $f a, 26$ to 33 in Bm-YELLOW- $b$ and the C-terminal of Bm-YELLOW- $d$ and Bm-YELLOW- $b$. The above information indicated that complicated divergence existed in the Bm YELLOW protein family.

The phylogenetic tree was calculated from the aligned protein sequences using the neighbor-joining (NJ) method (Figure 2). The Bombyx mori YELLOW protein family, Apis mellifera YELLOW and Drosophila YELLOW formed three monophyletic groups independently. In the Bm YELLOW protein family group, $B m$-YELLOW underwent the earliest divergence within the family.Bm-YELLOW- $c$, Bm-YELLOW- $f a, B m$-YELLOW- $f b$ and Bm-YELLOW- $f 2$ might be classified into one paraphyletic sub-group. The other paraphyletic sub-group included Bm-YELLOW- $d$ and BmYELLOW- $b$. The protein distance analysis showed that there was moderation support for an earliest divergence of $B m$-YELLOW among the known members. The results of phylogenetic analyses showed that the Bm YELLOW protein family genes clearly formed a monophyletic group distant from Apis mellifera and Drosophila melanogaster.

\section{Tissue expression patterns of Bm YELLOW protein family} The RT-PCR was done to analyze tissue specific expression patterns of the $B m$ YELLOW protein family genes on the $3^{\text {rd }}$ and the $8^{\text {th }}$ days (matured silkworm) of the $5^{\text {th }}$ instar larvae (Figure 3). The tissues included head, wing discs, midgut, silk glands, fat body, malpighian tubules, body wall, hemocyte, trachea, and gonads (testis and ovary). Bm-yellow-d and Bm-yellow-b were transcripted in all the tissues, therein a low expression was observed of Bm-yellow-d in silk glands and Bm-yellow-b in the testis of matured silkworm.Bm-yellow-fa was obviously found not expressed in hemocyte. Notably high levels of Bm-yellow-c transcripts were readily detectable in all tissues except hemocyte. Bm-yellow- $f b$ was not found in malpighian tubules, midgut and silk glands but found in others. Bmyellow- $f 2$ was only expressed in head, wing discs, body wall, pheromone gland and trachea. Bm-yellow, which was most similar to Dm-yellow, was expressed in most of the organs studied in the experiment. But it was hardly detectable in malpighian tubules, silk glands, fat body and body 

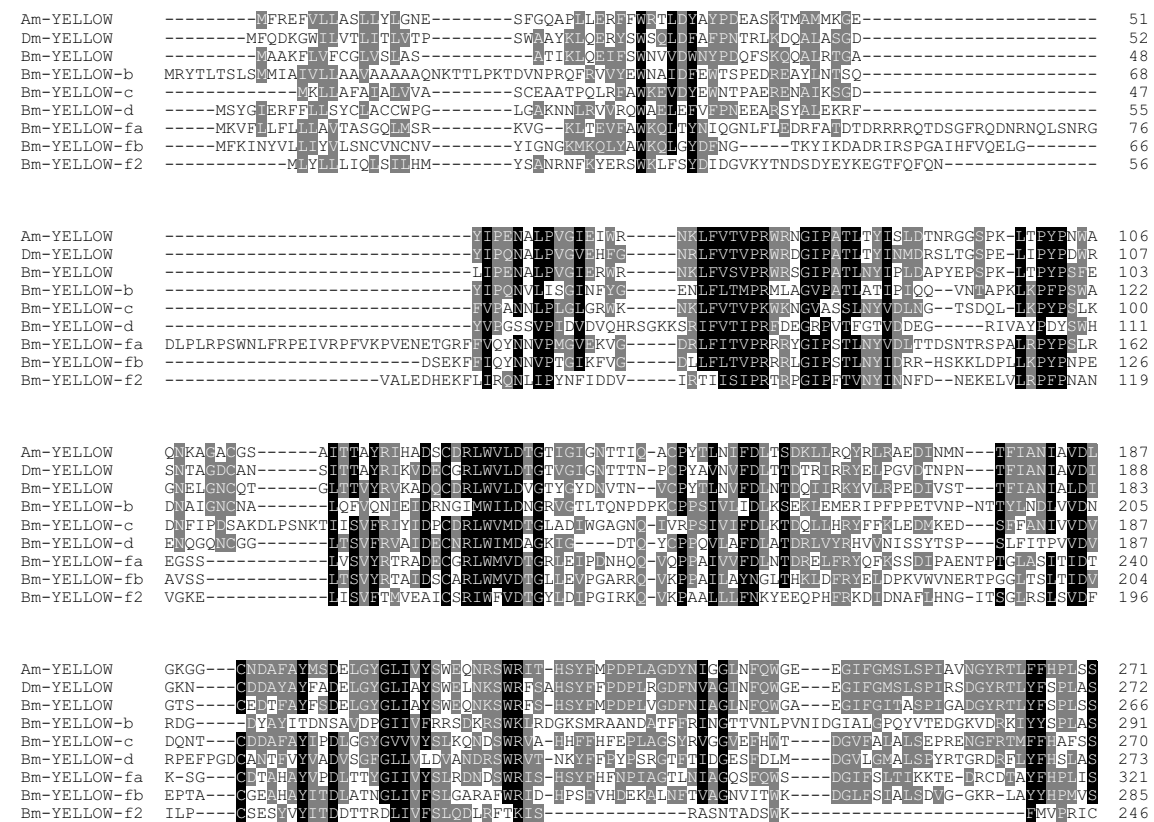

BM-YELLOW- $f 2$
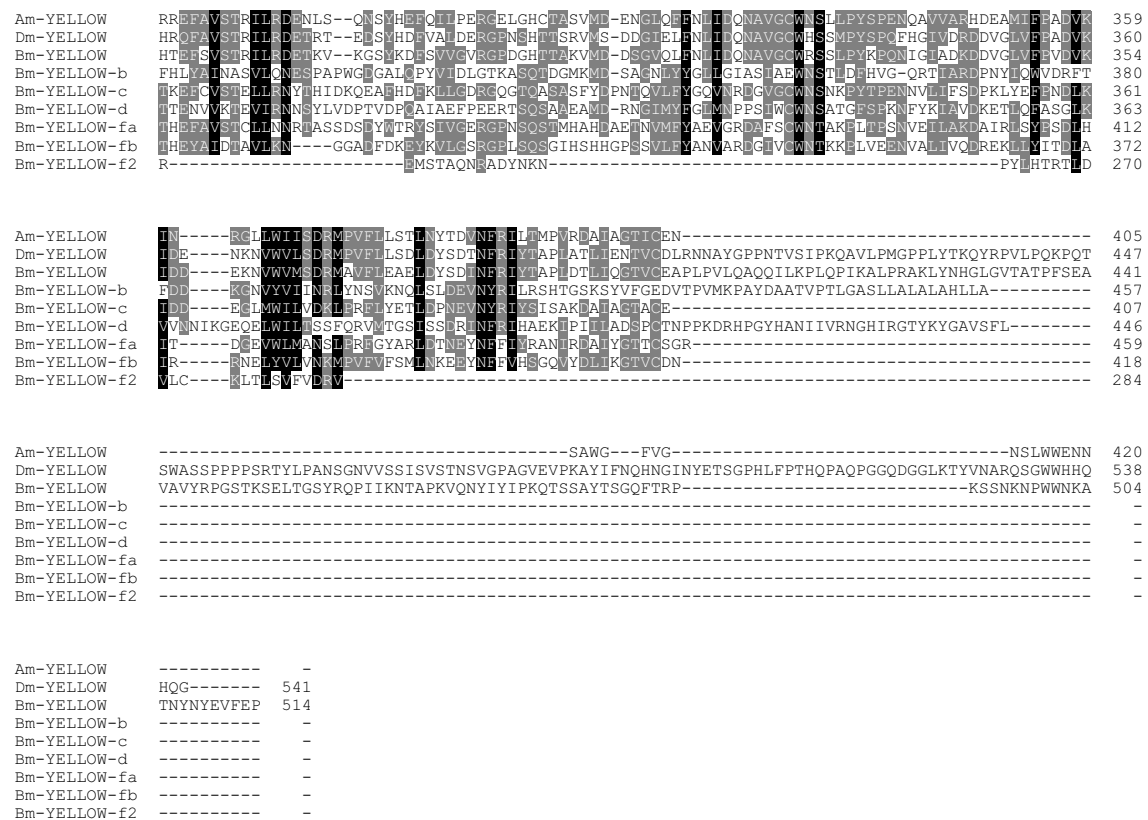

Figure I

Alignment of Bm-YELLOW proteins with that of $A$. mellifera and D. melanogaster. The protein sequences were aligned using CLUSTAL $X$ and visualized with Genedoc software. Amino acids that are similar in $90 \%$ of aligned sequences are shaded black, $40 \%-60 \%$ grey. 


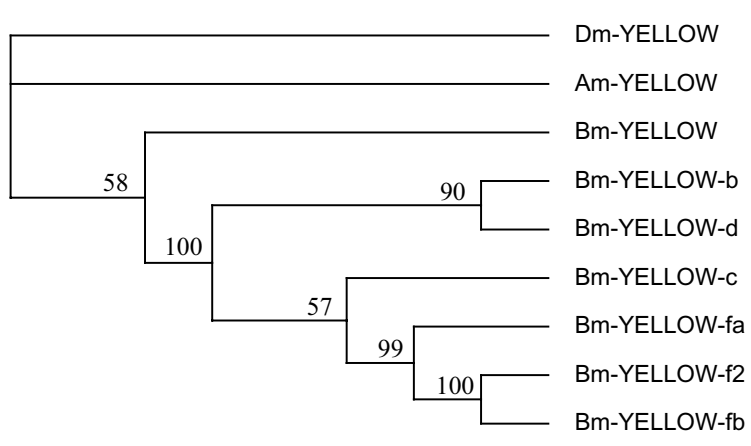

Figure 2

Phylogeny of YELLOW family proteins of B. mori. The numbers forks indicate the number of times the group consisting of the species which are to the right of that fork occurred among the trees, out of 100 trees.

wall. We would note that even all of the numbers of $\mathrm{Bm}$ yellow family had high expression level in gonads.

\section{Discussion}

We obtained seven genes coding proteins each contains a conserved MRJP domain from the present silkworm EST library and named the silkworm YELLOW protein family genes. Each protein in the family possessed a putative cleavable signal peptide composed of a hydrophobic sequence, 17 to 26 residues long at the N-terminal, and a MRJP conserved domain. In the SilkDB [21,22], seven genes predicted from the silkworm genome draft sequence, each possess a putative MRJP conserved domain have been named as Bmb004831, Bmb006279, Bmb006279, Bmb010554, Bmb026342, Bmb030806, and Bmb033954. However, our results are different from theirs.

For the confidence of $\mathrm{Bm}$ YELLOW protein family members, we designed primer1 and primer2 based on the EST sequences that included 5' non-coding region except $\mathrm{Bm}$ yellow- $d$. In order to validate the assemblage of Bm-yellow$d$, we designed two primers containing complete coding region (5'-atgtcgtacggaatcgagcgat-3' and 5'-ctacagaaatgacacagcgcc-3'), and successfully cloned the entire open reading frame from the midgut $\mathrm{cDNA}$. The length of $\mathrm{Bm}$ yellow- $f 2$ gene was the shortest and its MRJP conserved domain was truncated. But the search of its genomic sequence revealed that contig027742 (GenBank:

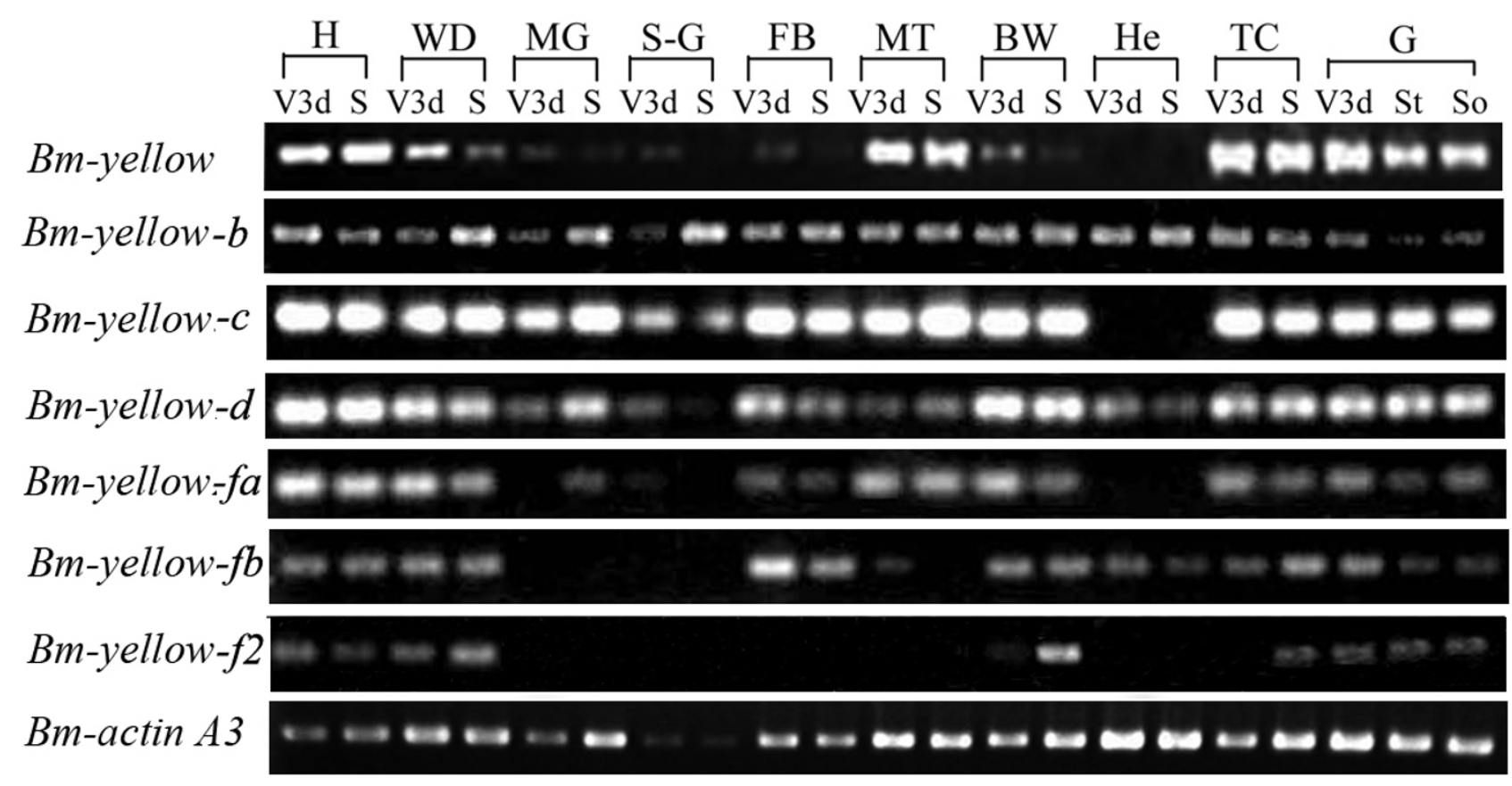

\section{Figure 3}

Tissue expression profiles of the yellow family genes of silkworm. RT-PCR of tissue templates including $H=$ head, WD = wing discs, $\mathrm{MG}=$ midgut, $\mathrm{SG}=$ silk glands, $\mathrm{FB}=$ fat body, $\mathrm{MT}=$ malpighian tubules, $\mathrm{BW}=$ body wall, $\mathrm{He}=$ hemocyte, $\mathrm{TC}=$ trachea cluster, $\mathrm{G}=$ gonad, $\mathrm{T}=$ testis, $\mathrm{O}=$ ovary. $\mathrm{V} 3 \mathrm{~d}=3^{\text {rd }}$ days of the $5^{\text {th }}$ instar larvae. $\mathrm{S}=8^{\text {th }}$ days of the $5^{\text {th }}$ instar larvae $($ the beginning of spinning). 
AADK01027742) covered all the sequence of the last exon (at the nucleotide acid site from 747 to 1,140 ). All the above results proved the credibility of the seven cloned $\mathrm{Bm}$ YELLOW protein genes.

The Apis mellifera MRJP/YELLOW family and the Drosophila melanogaster YELLOW family resulted from a series of events of a duplication and subsequent divergence [6]. What analysis of cDNA sequence and genomic structure of $\mathrm{Bm}$ YELLOW protein family genes of the silkworm demonstrated are as follows: on one hand, the seven complete members encoding various lengths of amino acids, 284 to 514 long, contained stretches of unique amino acid sequences in their coding regions; on the other hand, some of the 0-12 introns included extensive repeat sequences. But only 1-3 introns were included in the 14 yellow family members of Drosophila melanogaster. We assumed that the $B m$ YELLOW protein family also originated in the same manner, but the evolutionary procedure was more complex than that in Drosophila and Apis.

Nothing has been reported on the cloning and function of lepidopteran YELLOW protein family until recently. From the tissue expression profiles, we found that all the seven genes of the $B m$ YELLOW protein family were transcripted in head, wing discs, body wall and gonads (testis and ovary). As Bm-yellow-d and Bm-yellow-b were observed in every tissue and possessed similar tissue expression patterns, they were also classified into a paraphyletic subgroup in the phylogenetic tree. Then we could speculate that Bm-yellow-d and Bm-yellow-b had important roles in silkworm development and had similar physiological functions. The Bm-yellow- $f a, B m-y e l l o w-f b$ and Bm-yellow- $f 2$ had a similar distribution in the tissue expression profiles and had the best similarity to Drosophila yellow- $f$ and yellow-f2 which had the dopachrome-conversion enzyme activity. In addition, the three members were classified into a paraphyletic sub-group in the phylogenetic tree. These indicated that Bm-yellow- $f a, B m-y e l l o w-f b$ and Bmyellow- $f 2$ might have functions in pigmentation. Preliminary experiments showed that appearance of the pupa was dark black, similar to the phenotype of black pupa due to the over expression of Bm-yellow-d in pupal stage via a weakened pathogenic baculoviral Expression system (see Additional file 1). This indicated that Bm-yellow-d might be in a close relation with cuticle pigmentation too. The function of Drosophila YELLOW members is relative to reproduction, and studies showed that yellow-g and yellow$\mathrm{g} 2$ in Drosophila playing a female-specific role in egg development [23]. All the members of the Bm YELLOW protein family had a high transcription level in ovary and testis. This suggested that $B m$ YELLOW protein family were also involved to the reproduction.

\section{Conclusion}

Bombyx mori YELLOW protein family is the first reported MRJP/YELLOW family to date in the Lepidoptera. It is composed of at least seven members each has one MRJP domain. The low identity of their signal peptides and their MRJP conserved domains, and the highly diversity in cDNA and genomic structure and also unique tissue expression patterns indicated that the members of $\mathrm{Bm}$ YELLOW protein family might have various functions in the silkworm development.

\section{Methods}

\section{Insects and tissue dissection}

The silkworm stock Jingsong $\times$ Haoyue is maintained in our laboratory. The insects were reared on artificial diet at $25^{\circ} \mathrm{C}$ with $70 \%-80 \%$ relative humidity. Tissues were dissected out at proper developmental stages for the experiments.

\section{Database searching and sequence assembly}

The protein sequence of Drosophila melanogaster yellow (GenBank: AAF45497) was used to BLAST Bombyx mori EST database [24]. The obtained sequences were associated and catalogued by the use of DNASTAR software package [25] and CLUSTAL X software package [26]. The conserved domain was speculated by the Internet server [27] and the signal peptide was speculated through the SignalP 3.0 Server program [28]. The genomic DNA sequence was searched from the insect genomes with Bombyx-limited [29].

\section{3'-Rapid amplification of CDNA ends (3'-RACE) and DNA sequencing}

Total RNA was isolated from tissues using TRIZOL Reagent (Invitrogen) according to the standard protocol. All RNA samples were treated with Rnase free Dnase (Promega), and evaluated in agarose gels to ensure that they contained intact rRNA and were free of DNA contamination.

One microgramme of total RNA extracted from different tissues at given stages was used for 3'-RACE cDNA synthesis (BD SMART ${ }^{\mathrm{TM}}$ RACE cDNA Amplification Kit, Clontech), according to the user manual. PCR was performed with primer1 and Universal Primer A Mix (UPM, Clontech), then a nest PCR was used with primer2 and NUP using the suitable diluted former PCR product as the template. Each PCR reaction was carried out under the following conditions; after denaturing for $5 \mathrm{~min}$ at $95^{\circ} \mathrm{C}$, subsequent cooling on ice and addition of Taq DNA polymerase, PCR was performed 30 cycles of $94^{\circ} \mathrm{C}$ for 1 min, $60^{\circ} \mathrm{C}$ for $1 \mathrm{~min}$, and $72^{\circ} \mathrm{C}$ for $1-2 \mathrm{~min}$, followed by 10 min incubation at $72^{\circ} \mathrm{C}$. Primers used for $3^{\prime}$-RACE were listed in Table 2. 
The PCR products were separated on agarose gel by electrophoresis, purified and ligated into pMD18-Tvector (Takara). Several clones were sequenced by the dideoxynucleotide method with ABI-3730 automatic sequencer. DNA sequences were analyzed using DNASTAR and CLUSTAL X software packages.

The yellow-like family gene cDNAs obtained in Bombyx mori were submitted to the GenBank under the accession numbers listed in Table 1.

\section{Protein sequences alignment and phylogenetic analysis}

Yellow-like protein sequences were aligned and saved as PHYLIP format with CLUSTALX software package. Then a neighbor-joining (NJ) tree based on amino acid sequences was constructed by PHYLIP software package (100 bootstrap replicates).

\section{RT-PCR}

Two microgrammes of total RNA of the different tissues at proper stages were used to synthesize cDNAs according to the Reverse Transcription kit's protocol (Promega Cat.: A3500). Using the reverse transcription products as the templates, 30 cycles of amplification were performed in all the members of $B m$ YELLOW protein family with specific primers listed in Table 2. At the same time, the amplification of Bm-actin A3 cDNA (25 cycles) was used as a standardization control. The PCR products were separated on $1.5 \%$ agarose gel by electrophoresis.

\section{Authors' contributions}

AHX carried out RT-PCR and data analysis and wrote the manuscript. QXZ carried out tissue dissection, RNA extraction and the cDNA synthesis, participated in the design of the study and helped analyze the data and draft the manuscript. LLY participated in RT-PCR and data analysis. WGL and YZY carried out silkworm breeding and participated in tissue dissection. ZYZ and ZFZ conceived of the study, and participated in its design and coordination and helped to draft the manuscript. All authors read and approved the final manuscript.

\section{Additional material}

\section{Additional File 1}

Over expression of Bm-yellow-d in pupal stage via a weakened pathogenic baculoviral Expression system. A. Intact one; B. Injected the weak hybridization baculovirus which contained the beta-galactosidase gene which is driven by polyhedrin promoter as the control; C. Injected a weak hybridization baculovirus which contained the Bm-yellow-d gene is driven by ie-1 promoter and $\mathrm{hr} 3$ enhancer expression cassette in the pupa at early stage. From the pictures we could find that the pupa in $C$ is darkened comparing with the controls ( $A$ \& B). It is known that the Drosophila yellow gene is related to normal larval and adult pigmentation, so we thought that the darkness of the pupa in $C$ might be caused by the abundant expression of Bm-yellow-d. But we want to declare that the present results are preliminary, and further work is doing in our lab to prove the deduction.

Click here for file

[http://www.biomedcentral.com/content/supplementary/14712164-7-195-S1.pdf]

\section{Acknowledgements}

This work was supported by financial grants from The National Basic Research Program of China (973 Program, No. 2005CB I 21006), National High Technology Research and Development Program of China (863 Major Program, No. 2005AA206120), and National Natural Science Foundation of China (No. 30470034). We thank Zhenzhen Yang for the language editing of our manuscript.

\section{References}

I. Maleszka R, Kucharski R: Analysis of Drosophila yellow-B cDNA reveals a new family of proteins related to the Royal Jelly proteins in the honeybee and to an orphan protein in an unusual bacterium Deinococcus radiodurans. Biochem Biophys Res Commun 2000, 270:773-776.

2. Albert S, Klaudiny J: The MRJP/YELLOW protein family of Apis mellifera: Identification of new members in the EST library. J Insect Physiol 2004, 50:5 I-59.

3. Schmitzova J, Klaudiny J, Albert S, Schroeder W, Schreckengost W, Hanes J, Judova J, Simuth J: A family of major royal jelly proteins of the honeybee Apis mellifera L. Cell Mol Life Sci 1998, 54:1020-1030.

4. Albert S, Klaudiny J, Simuth J: Molecular characterization of MRJP3, highly polymorphic protein of honeybee (Apis mellifera) royal jelly. Insect Biochem Mol Biol 1999, 29:427-434.

5. Kucharski R, Maleszka R, Hayward DC, Ball EE: A royal jelly protein is expressed in a subset of Kenyon cells in the mushroom bodies of the honeybee brain. Naturwissenschaften 1998, 85:343-346

6. Albert S, Bhattacharya D, Klaudiny J, Schmitzova J, Simuth J: The family of major royal jelly proteins and its evolution. J Mol Evol 1999, 49:290-297.

7. Simuth J, Bilikova K, Kovacova E, Kuzmova Z, Schroder W: Immunochemical approach to detection of adulteration in honey: physiologically active royal jelly protein stimulating TNFalpha release is a regular component of honey. J Agric Food Chem 2004, 52:2154-2158.

8. Gompel N, Prudhomme B, Wittkopp PJ, Kassner VA, Carroll SB: Chance caught on the wing: cis-regulatory evolution and the origin of pigment patterns in Drosophila. Nature 2005, 433:48I-487.

9. Drapeau MD, Cyran SA, Viering MM, Geyer PK, Long AD: A cis-regulatory sequence within the yellow locus of Drosophila melanogaster required for normal male mating success. Genetics 2006, 172:1009-1030.

10. Drapeau MD, Radovic A, Wittkopp PJ, Long AD: A gene necessary for normal male courtship, yellow, acts downstream of fruit- 
less in the Drosophila melanogaster larval brain. I Neurobiol 2003, 55:53-72.

II. Adams MD, Celniker SE, Holt RA, Evans CA, Gocayne JD, Amanatides PG, Scherer SE, Li PW, Hoskins RA, Galle RF, George RA, Lewis SE, Richards S, Ashburner M, Henderson SN, Sutton GG, Wortman JR, Yandell MD, Zhang Q, Chen LX, Brandon RC, Rogers YH, Blazej RG, Champe M, Pfeiffer BD, Wan KH, Doyle C, Baxter EG, Helt G, Nelson CR, Gabor GL, Abril JF, Agbayani A, An HJ, Andrews-Pfannkoch C, Baldwin D, Ballew RM, Basu A, Baxendale J, Bayraktaroglu L, Beasley EM, Beeson KY, Benos PV, Berman BP, Bhandari D, Bolshakov S, Borkova D, Botchan MR, Bouck J, Brokstein P, Brottier P, Burtis KC, Busam DA, Butler H, Cadieu E, Center A, Chandra I, Cherry JM, Cawley S, Dahlke C, Davenport LB, Davies P, de Pablos B, Delcher A, Deng Z, Mays AD, Dew I, Dietz SM, Dodson K, Doup LE, Downes M, Dugan-Rocha S, Dunkov BC, Dunn P, Durbin KJ, Evangelista CC, Ferraz C, Ferriera S, Fleischmann W, Fosler C, Gabrielian AE, Garg NS, Gelbart WM, Glasser K, Glodek A, Gong F, Gorrell JH, Gu Z, Guan P, Harris M, Harris NL, Harvey D, Heiman TJ, Hernandez JR, Houck J, Hostin D, Houston KA, Howland TJ, Wei MH, Ibegwam C, Jalali M, Kalush F, Karpen GH, Ke Z, Kennison JA, Ketchum KA, Kimmel BE, Kodira CD, Kraft C, Kravitz S, Kulp D, Lai Z, Lasko P, Lei Y, Levitsky AA, Li J, Li Z, Liang Y, Lin X, Liu X, Mattei B, McIntosh TC, McLeod MP, McPherson D, Merkulov G, Milshina NV, Mobarry C, Morris J, Moshrefi A, Mount SM, Moy M, Murphy B, Murphy L, Muzny DM, Nelson DL, Nelson DR, Nelson KA, Nixon K, Nusskern DR, Pacleb JM, Palazzolo M, Pittman GS, Pan S, Pollard J, Puri V, Reese MG, Reinert K, Remington K, Saunders RD, Scheeler F, Shen H, Shue BC, SidenKiamos I, Simpson M, Skupski MP, Smith T, Spier E, Spradling AC, Stapleton M, Strong R, Sun E, Svirskas R, Tector C, Turner R, Venter E, Wang $A H$, Wang $X$, Wang ZY, Wassarman DA, Weinstock GM, Weissenbach J, Williams SM, Woodage T, Worley KC, Wu D, Yang S, Yao QA, Ye J, Yeh RF, Zaveri JS, Zhan M, Zhang G, Zhao Q, Zheng L, Zheng XH, Zhong FN, Zhong W, Zhou X, Zhu S, Zhu X, Smith HO, Gibbs RA, Myers EW, Rubin GM, Venter JC: The genome sequence of Drosophila melanogaster. Science 2000, 287:2185-2195.

12. Drapeau MD: The Family of Yellow-Related Drosophila melanogaster Proteins. Biochem Biophys Res Commun 200I, 28I:6||-6|3.

13. Wittkopp PJ, True JR, Carroll SB: Reciprocal functions of the Drosophila yellow and ebony proteins in the development and evolution of pigment patterns. Development 2002, 129:1849-1858.

14. Han Q, Fang J, Ding H, Johnson JK, Christensen BM, Li J: Identification of Drosophila melanogaster yellow- $f$ and yellow- $f 2$ proteins as dopachrome-conversion enzymes. Biochem J 2002, 368:333-340.

15. Volf P, Skarupova S, Man P: Characterization of the lectin from females of Phlebotomus duboscqi sand flies. Eur J Biochem 2002, 269:6294-630I.

16. White O, Eisen JA, Heidelberg JF, Hickey EK, Peterson JD, Dodson RJ, Haft DH, Gwinn ML, Nelson WC, Richardson DL, Moffat KS, Qin $H$, Jiang L, Pamphile W, Crosby M, Shen M, Vamathevan J], Lam P, McDonald L, Utterback T, Zalewski C, Makarova KS, Aravind L, Daly MJ, Minton KW, Fleischmann RD, Ketchum KA, Nelson KE, Salzberg $\mathrm{S}$, Smith HO, Venter JC, Fraser CM: Genome sequence of the radioresistant bacterium Deinococcus radiodurans $\mathbf{R} I$. Science 1999, 286: I57|-1517.

17. Cheng D, Xia Q, Zhou Z, Lu C, Xiang Z: cDNA Libraries Construction and Large scale ESTs Sequencing of the Silkworm. Can Ye Ke Xue 2003, 29:335-339.

18. Mita K, Morimyo M, Okano K, Koike Y, Nohata J, Kawasaki H, Kadono-Okuda K, Yamamoto K, Suzuki MG, Shimada T, Goldsmith MR, Maeda S: The construction of an EST database for Bombyx mori and its application. Proc Natl Acad Sci USA 2003, 100:14I2I-14126.

19. Xiang ZH: Silkworm Genome Project and the Silk Road in the 2I th Century in China. Can Ye Ke Xue 2003, 29:32I-322.

20. Mita K, Kasahara M, Sasaki S, Nagayasu Y, Yamada T, Kanamori H, Namiki N, Kitagawa M, Yamashita H, Yasukochi Y, Kadono-Okuda K, Yamamoto K, Ajimura M, Ravikumar G, Shimomura M, Nagamura Y, Shin-I T, Abe H, Shimada T, Morishita S, Sasaki T: The genome sequence of silkworm, Bombyx mori. DNA Res 2004, I I:27-35.

21. Silkworm Knowledgebase [http://silkworm.genomics.org.cn]

22. Wang J, Xia Q, He X, Dai M, Ruan J, Chen J, Yu G, Yuan H, Hu Y, Li R, Feng T, Ye C, Lu C, Wang J, Li S, Wong GK, Yang H, Wang J, Xiang
Z, Zhou Z, Yu J: SilkDB: a knowledgebase for silkworm biology and genomics. Nucleic Acids Res 2005, 33:399-402.

23. Claycomb JM, Benasutti M, Bosco G, Fenger DD, Orr-Weaver TL: Gene amplification as a developmental strategy: isolation of two developmental amplicons in Drosophila. Dev Cell 2004, 6:145-155.

24. NCBI BLAST [http://www.ncbi.nlm.nih.gov/BLAST]

25. Burland TG: DNASTAR's lasergene sequence analysis software. Methods Mol Biol 2000, I32:7|-9I.

26. Thompson J, Gibson T, Plewniak F, Jeanmougin F, Higgins D: The CLUSTAL_ $X$ windows interface: flexible strategies for multiple sequence alignment aided by quality analysis tools. Nucleic Acids Res 1997, 25:4876-4882.

27. NCBI Conserved Domains [http://www.ncbi.nlm.nih.gov/Struc ture/cdd/wrpsb.cgi]

28. SignalP 3.0 Server [http://www.cbs.dtu.dk/services/SignalP]

29. NCBI BLAST with arthropoda genomes [http:// www.ncbi.nlm.nih.gov/sutils/genom table.cgi?organism=insects]
Publish with Biomed Central and every scientist can read your work free of charge

"BioMed Central will be the most significant development for disseminating the results of biomedical research in our lifetime. "

Sir Paul Nurse, Cancer Research UK

Your research papers will be:

- available free of charge to the entire biomedical community

- peer reviewed and published immediately upon acceptance

- cited in PubMed and archived on PubMed Central

- yours - you keep the copyright

Submit your manuscript here:

http://www.biomedcentral.com/info/publishing_adv.asp
BioMedcentral 